\title{
ANALISIS PENERIMAAN PAJAK KENDARAAN BERMOTOR DAN BEA BALIK NAMA KENDARAAN BERMOTOR DI KABUPATEN MINAHASA SELATAN
}

\author{
Fikram Pratama A. Karim ${ }^{1}$, Stanly W. Alexander ${ }^{2}$ Jessy D.L Warongan ${ }^{3}$ \\ 1,2,3 Jurusan Akuntansi, Fakultas Ekonomi dan Bisnis, Universitas Sam Ratulangi, Jl. Kampus Bahu, Manado \\ 95115, Indonesia
}

E-mail : ikamkarim2@gmail.com

\begin{abstract}
To fulfill the interests of the people, where the need for these funds increases every year along with the increase in population and the needs of the people. The funds that will be spent on this development are certainly obtained from the people themselves through a collection called tax. The purpose of this study was to determine motor vehicle tax revenue and the transfer fee of motor vehicle names in the South Minahasa regency and what obstacles / efforts were made by the government to increase tax revenues. The analytical method used in this study is a qualitative method with descriptive data analysis techniques. The results showed that the procedures for calculating PKB and BBNKB of South Minahasa Samsat UPTD had followed local regulation No.7 of 2011, and PKB collection for each year for collection of $B B N K B$.
\end{abstract}

Keywords: Motor vehicle reception tax, duty of transferring name of a motor vehicle

\section{PENDAHULUAN}

Dasar Hukum pemungutan Pajak Daerah dan Retribusi Daerah adalah Perda No 7 Tahun 2011 mengenai Pajak Daerah dan Retribusi Daerah. Pajak Daerah yaitu kontribusi wajib pada daerah yang terutang oleh kalangan pribadi atau badan yang bersifat memaksa berdasarkan peraturan daerah, dengan tidak mendapat imbalan secara langsung dan digunakan sebagai keperluan daerah bagi sebesar-besarnya untuk kemakmuran rakyat.

Pajak kendaraan bermotor (PKB) adalah sumber pendapatan daerah yang terbesar dan selalu mengalami peningkatan dari tahun ke tahun, sama halnya dengan bea balik nama kendaraan bermotor (BBNKB) adalah sumber pendapatan daerah yang terbesar, akan tetapi bea balik nama kendaraan bermotor mengalami fluktuasi dalam penerimaan pajak. PKB dan BBNKB dapat dilihat berdasarkan tabel dibawah ini:

Tabel 1. Target dan Realisasi Penerimaan Pajak Kendaraan Bermotor

\begin{tabular}{cccr}
\hline No & Tahun & Target $(\mathbf{R p )}$ & Realisasi (Rp) \\
\hline 1 & 2015 & 9.984 .837 .000 & 11.732 .142 .100 \\
2 & 2016 & 9.742 .121 .000 & 12.258 .058 .000 \\
3 & 2017 & 12.078 .175 .300 & 13.174 .621 .287 \\
\hline
\end{tabular}

Sumber Data: UPTD Samsat Minahasa Selatan, 2018

Tabel 2. Target dan Realisasi Penerimaan Bea Balik Nama Kendaraan Bermotor

\begin{tabular}{cccc}
\hline No & Tahun & Target $(\mathbf{R p )}$ & Realisasi (Rp) \\
\hline 1 & 2015 & 16.621 .575 .000 & 12.508 .215 .000 \\
2 & 2016 & 12.550 .135 .000 & 13.179 .018 .025 \\
3 & 2017 & 12.731 .973 .500 & 12.106 .938 .250 \\
\hline
\end{tabular}

Sumber Data: UPTD Samsat Minahasa Selatan 
Tabel diatas menunjukkan target dan realisasi Pajak Kendraan Bermotor dan Bea Balik Nama Kendaraan Bermotor Kabupaten Minahasa Selatan tahun 2015-2017. Dari Tabel 1 dapat dilihat bahwa realisasi Pajak Kendaraan Bermotor (PKB) dari tahun 2015-2017 mengalami peningkatan. Dengan adanya peningkatan tersebut menunjukan bahwa kepemilikan kendaraan bermotor di Kabupaten Minahasa Selatan terus meningkat setiap tahunnya dan selalu melebihi target. Sedangkan perkembangan pada tabel 1.2 setiap tahunnya terlihat rata-rata menunjukkan bahwa tidak tercapainya target penerimaan Bea Balik Nama Kendaraan Bermotor, hanya pada tahun 2016 yang mencapai target. Berdasarkan rumusan masalah di atas, maka tujuan dari penelitian ini adalah.

1. Untuk mengetahui prosedur penerimaan pajak kendaran bermotor dan bea balik nama kendaraan bermotor yang ada di kabupaten Minahasa Selatan.

2. Untuk mengetahui kendala dalam peningkatan penerimaan Pajak kendaran bermotor dan bea balik nama kendaraan bermotor yang ada di kabupaten Minahasa Selatan.

3. Untuk mengetahui upaya dalam peningkatan penerimaan Pajak kendaran bermotor dan bea balik nama kendaraan bermotor yang ada di kabupaten Minahasa Selatan

\section{TINJAUAN PUSTAKA}

Pengertian Pajak. Waluyo (2013:2) mengemukakan pendapat oleh pakar mengenai definisi pajak, yaitu sebagai berikut :

J.H Smeets : "Pajak adalah prestasi kepada pemerintah yang terutang melalui norma-norma umum dan yang dapat dipaksakannya, tanpa adanya kontra-prestasi yang dapat ditujukkan dalam hal individual maksudnya adalah untuk membiayai pengeluaran pemerintah".

Pendapatan Asli Daerah. Kaho (2010:210) : "Dalam sistem desentralisasi, daerah berhak merencanakan, menggali, mengolah dan menggunakan keuangan daerah sesuai dengan daerah untuk pendapatan asli daerah-nya'.

Perhitungan Pajak Kendaraan Bermotor. Siahaan (2016:91) : "Besarnya pokok pajak dihitung dengan cara mengalihkan tarif pajak dengan dasar pengenaan pajak. Cara perhitungan ini digunakan untuk setiap jenis pajak daerah, yang juga merupakan dasar perhitungan untuk semua jenis pajak pusat".

Perhitungan Bea Balik Nama Kendaraan Bermotor. Besaran pokok BBNKB yang terutang dihitung dengan cara mengalikan tarif pajak dengan dasar pengenaan pajak. Secara umum perhitungan BBNKB adalah sesuai dengan rumus berikut :

Pajak Terutang = Tarif Pajak $\mathrm{x}$ Dasar Pengenaan Pajak

$=$ Tarif Pajak x Nilai Jual Kendaraan Bermotor

Penelitian Terdahulu. Ofoegbu N. Grace (2016) dengan "judul Analisis Empiris dan Pengaruh Pajak Pendapatan Terhadap Ekonomi Pengambangan Nigeria. Tujuan penelitian yaitu untuk menguji pengaruh penerimaan pajak pada perkembangan ekonomi Nigeria, dan untuk memastikan apakah ada perbedaan dalam menggunakan IPM dan PDB dalam membangun hubungan. Metode penelitian ini adalah deskriptif. Hasil penelitian yang didapat adalah hubungan antara penerimaan pajak dan pembangunan. Hasil ini juga mengungkapkan bahwa mengukur pengaruh penerimaan pajak atas pembangunan ekonomi menggunakan IPM memberikan hubungan yang lebih rendah dari pada mengukur hubungan dengan PDB sehingga menunjukan bahwa menggunakan produk domestik bruto (PDB) memberikan gambaran yang dilukis tentang hubungan tersebut. Antara penerimaan pajak dan pembangunan ekonomi di Nigeria. Persamaan dalam penelitian ini yaitu metode penelitian dan variabel penerimaan pajak. Perbedaan dalam penelitian ini objek. Babatunde A. Onakoya (2016) dengan "judul Perpajakan dan Pertumbuhan Ekonomi di Nigeria. Tujuan penelitian yaitu kointegrasi antara penerimaan pajak dan pertumbuhan ekonomi di Nigeria dari tahun 1980 hingga 2013. Metode penelitian ini adalah kualitatif. Hasil penelitian yang didapat yaitu menunjukan bahwa hubungan jangka panjang antara perpajakan dan pertumbuhan ekonomi 
di Nigeria hasilnya juga mengungkapkan hubungan positif yang signifikan yang pada tingkat signifikansi $5 \%$ antara pajak minyak, pajak penghasilan perusahaan, dan pertumbuhan ekonomi. Namun komponen pajak secara bersama tidak signifikan dalam mempengaruhi pertumbuhan ekonomi Nigeria. Persamaan pada penelitian ini yaitu dalam metode penelitian dan variabel perpajakan. Perbedaan dalam penelitian ini yaitu objek.

\section{METODE PENELITIAN}

Jenis Penelitian. Penelitian ini menggunakan penelitian kualitatif deskriptif untuk menganalisis penerimaan pajak kendaraan bermotor dan bea balik nama kendaraan bermotor. Yang bertujuan untuk mengumpulkan data penelitian yang diperoleh dari kantor, kemudian diuraikan secara rinci untuk mengetahui permasalahan yang terjadi dan kemudian mencari penyelesaiannya.

Tempat Penelitian. Penelitian dilakukan pada Kantor Bersama Samsat Minahasa Selatan Jln. Trans Sulawesi Kel. Pondang Kec. Amurang Timur.

Jenis dan Sumber Data. Penelitian ini menggunakan metode kualitatif. Metode kualitatif yaitu data yang tidak dinyatakan dalam bentuk numerik yang berupa gambaran deskriptif dalam bentuk uraian seperti gambaran umum perusahaan, visi dan misi, struktur organisasi, hasil wawancara dengan instansi pihak terkait dan mengumpulkan dokumen-dokumen yang dibutuhkan seperti target dan realisasi penerimaan.

Teknik Pengumpulan Data. Teknik pengumpulan data yang dilakukan dalam penelitian ini yaitu wawancara.

Metode Analisis. Penelitian ini merupakan penelitian deskriptif, yaitu dengan menganalisis tentang pelaksanaan pemungutan pajak kendaraan bermotor dan bea balik nama kendaraan bermotor di Kabupaten Minahasa Selatan.

\section{HASIL PENELITIAN DAN PEMBAHASAN}

\subsection{Gambaran Umum Objek Penelitian}

Pada Tahun 2008 dengan di tetapkannya Peraturan Pemerintah Nomor 41 Tahun

2008 tentang Organisasi Perangkat Daerah, maka Dinas Pendapatan menjadi Dinas Pendapatan Dearah berdasarkan Peraturan Daerah Provinsi Sulawesi. Pada tahun tersebut, kantor Samsat Pembantu Amurang, Airmadidi dan Tomohon di tetapkan menjadi UPDT sehingga Dinas Pendaptan Daerah memiliki 8 UPDT.

Pada tahun 2011 ditetapkan UPTD baru pada Kabupaten Kepulauan Talaud, Kabupaten Kepulauan Sitaro, Kabupaten Bolaang Mongondow, Kabupaten Minahasa Tenggara, Kabupaten Bolaang Mongondow Timur, Kabupaten Bolaang Mongondow Selatan, dan Kabupaten Bolaang Mongondow Utara seiring dengan berdirinya daerah otonom baru sehingga Dispenda memiliki 15 UPTD dan 4 Samsat Pembantu. Pada Tahun 2017 Dinas Pendapatan Daerah berubah menjadi Badan Pengelola Pajak dan Retribusi Daerah.

\subsection{Hasil Penelitian}

Prosedur Penerimaan Pajak Kendaraan Bermotor dan Bea Balik Nama

Kendaraan Bermotor. Prosedur pembayaran yang ada di perusahaan sudah memakai SOP (Standard Operating Procedure) dengan alur :

1. Koordinasi/Konfirmasi kesiapan sistem, petugas dan pedoman

2. Wajib Pajak ke loket informasi untuk mendapatkan info tentang pembayaran Pajak Kendaraan Bermotor dan Prosedur Balik Nama STNK

3. Petugas informasi memberi formulir pendaftaran untuk diisi, memberi nomor antrian dan mengarahkan Wajib Pajak ke loket antrian untuk menunggu panggilan

4. Petugas pendaftaran memanggil dan memeriksa kelengkapan berkas, lalu mengarahkan Wajib Pajak agar menunggu panggilan petugas Bank untuk melakukan pembayaran

5. Pendaftaran dan penyelidikan berkas oleh petugas kepolisian 
6. Penetapan jumlah SWDKLLJ oleh petugas Jasa Raharja

7. Petugas SKUM/KOHIR memeriksa kwitansi jual beli dan Surat Fiskal dan petugas penetapan menetapkan besar pajak sesuai ketentuan

8. Petugas korektor mengoreksi jumlah pajak, nama, alamat, tanggal jatuh tempo, tahun berlaku, mengisi jumlah STNK,TNKB dan menerbitkan slip bayar

9. Petugas Bank menerima berkas dan slip bayar lalu memanggil Wajib Pajak untuk membayar Prosedur pembayaran yang ada di perusahaan sudah memakai SOP (Standard Operating Procedure)

10. Setelah membayar, Wajib Pajak menunggu di loket penyerahan SKPD dan STNK

11. Berkas diterima oleh petugas pencetakan untuk menerbitkan SKPD,STNK dan TNKB

12. Validasi SKPD dan Arsip SKPD

Dasar Pengenaan Pajak Kendaraan Bermotor dan Bea Balik Nama Kendaraan Bermotor. Dasar Pengenaan Pajak Kendaraan Bermotor dan Bea Balik Nama Kendaraan Bermotor dihitung berdasarkan tabel yang dikeluarkan oleh menteri dalam negeri, dimana permendagri tersebut setiap tahun menyesuaikan atau setiap tahun dalam pengenaan perhitungan pajak dikeluarkan permendagri yang baru. Contohnya Tahunnya keluar permendagri nomor 28 Tahun 2017 dan permendagri no 68 Tahun 2018. Artinya Ketika ada jenis kendaraan yang tidak tertera pada permendagri baru (Tahun 2018) Masih dapat mengacu atau melihat cara perhitungan atau besarnya berdasar permendagri sebelumnya yaitu Tahun 2017.

Tarif Pajak Kendaraan Bermotor. Tarif Pajak Kendaraan Bermotor di UPTD Minsel sudah menerapkan atau mengikuti Peraturan Daerah Provinsi Sulawesi Utara No. 7 Tahun 2011 mengenai Pajak Daerah, yang telah diatur sebagai berikut :

1. Pada kepemilikan kendaraan bermotor pertama atau pembelian peratam dengan sebesar $1,5 \%$ (satu koma lima persen).

2. Pada kepemilikan kendaraan bermotor kedua dan seterusnya yaitu tarif ditetapkan secara progresif, yaitu sebagai berikut: (a) pada kepemilikan kedua sebesar 2\% (dua persen); dan (b) pada kepemilikan ketiga sebesar 2,5\% (dua koma lima persen).

Tarif Bea Balik Nama Kendaraan Bermotor. Tarif bea balik nama kendaraan bermotor di UPTD Minsel sudah menerapkan atau mengikuti Perda Provinsi Sulawesi Utara No. 7 Tahun 2011 tentang Pajak Daerah, diatur sebagai berikut:

1. Untuk tarif Bea Balik Nama Kendaraan Bermotor sebagai berikut:

a. Pada penyerahan pertama ditetapkan sebesar 12,5\% (dua belas koma lima persen).

b. Pada penyerahan kedua sampai seterusnya sebesar $1 \%$ (satu persen).

2. Untuk kendaraan bermotor alat-alat berat dan alat-alat besar yang tidak menggunakan jalan umum, tarif Bea Balik Nama Kendaraan Bermotor sebagai berikut :

a. Pada penyerahan pertama sebesar $0,75 \%$ (nol koma tujuh puluh lima persen).

b. Pada penyerahan kedua dan seterusnya sebesar $0,075 \%$ (nol koma nol tujuh puluh lima persen).

\section{Perhitungan Pajak Kendaraan Bermotor}

1.Untuk tarif pajak kendaraan bermotor pemilik pertama berdasarkan Perda No. 7 Tahun 2011 Sebesar $1,5 \%$.

2.Nilai Jual Kendaraan Bermotor untuk sepeda motor merek motor Yamaha dengan tipe 14D dengan tahun pembuatan 2012 senilai Rp.14.000.000.

3.Bobot sepeda motor Yamaha dengan tipe 14D dengan tahun pembuatan 2012 sebanyak 1 unit.

Besarnya pokok Pajak Kendaraan Bermotor yang terutang tersebut adalah:

$\mathrm{PKB}=$ Tarif $\mathrm{X}$ DPP

$$
=\text { Tarif } \mathrm{X}(\mathrm{NJKB} X \text { Bobot })
$$

$\mathrm{PKB}=(1,5 \%) \times(\mathrm{Rp} .14 .000 .000 \times 1)$ 


$$
\begin{aligned}
& =1,5 \% \text { X Rp. } 14.000 .000 \\
& =\text { Rp. } 210.000
\end{aligned}
$$

Perhitungan Bea Balik Nama Kendaraan Bermotor. Untuk Kendaraan Bermotor Baru (BBNKB ) Sesuai dengan Peraturan Menteri Dalam Negeri Republik Indonesia No.12 Tahun 2016 diperoleh data sebagai berikut :

a. Jenis : Mobil Penumpang-sedan

b. Merk : Ford

c. Tipe : Fiesta sedan 1.0L AT-Titanium

d. Tahun Pembuatan : 2016

e. Nilai jual kendaraan Bermotor ford dengan tipe fiesta sedan 1. OL AT-Titanium adalah sebesar Rp 240.000.000 (Kolom 6 Peraturan Dalam Negeri Republik Indonesia No 12 Tahun 2016 )

Besarnya pokok BBNKB yang terutang.:

$\mathrm{BBNKB}=$ Tarif $\mathrm{x}$ NJKB

$$
\begin{aligned}
& =12.5 \% \text { X Rp. } 240.000 .000 \\
& =30.000 .000
\end{aligned}
$$

\section{Kendala Penerimaan Pajak Kendaraan Bermotor dan BBNKB UPTD Minsel}

1. Kepatuhan Wajib Pajak

Kepatuhan wajib pajak terhadap pemindahtanganan kendaraan bermotor tanpa melakukan balik nama menjadi salah satu kendala dalam pemungutan pajak kendaraan bermotor maupun bea balik nama kendaraan bermotor pada UPTD Samsat Wilayah Minsel.

2. Data Wajib Pajak berbeda pada sistem dan dilapangan

Petugas Sering kali mendapatkan data wajib pajak dalam sistem pajak kendaraan bermotor seperti alamat rumah serta nomor telepon yang bisa di hubungi berbeda dengan informasi yang didapatkan setelah petugas turun langsung di lapangan.

3. Kurangnya Pengetahuan Wajib Pajak

kurangnya pengetahuan sering kali menjadi kendala dalam penerimaan, dikarenakan kurangnya petugas UPTD Samsat Minsel dalam melakukan penyebaran mengenai informasi tentang pengenaan tarif progresif pajak kendaraan bermotor.

Upaya/ Strategi Untuk Meningkatkan Penerimaan Pajak Kendaraan Bermotor Dan BBNKB UPTD Minsel

1. Komunikasi

Dalam hal ini kita harus melakukan sosialisasi disetiap bidang, yaitu dengan membuat sosialisasi di media massa dan media sosial. Hal ini jelas bahwa dengan adanya sosialisasi tentang betapa pentingnya peran pajak kendaraan bermotor dan bea balik nama kendaraan bermotor pada Pendapatan Asli Daerah, agar supaya masyarakat atau wajib pajak mengerti dan bisa terdorong untuk melakukan kewajibannya membayar pajak.

2. Kerjasama dengan Kepolisian

Bekerja sama dengan kepolisian contohnya sepeti melakukan Razia agar bisa mencari dan mendapatkan wajib pajak yang belum atau tidak melakukan kewajibannya untuk membayar pajak.

3. Sistem Pelayanan

Untuk membuat wajib pajak merasa nyaman dalam proses melaksanakan kegiatan pembayaran pajak, ada beberapa cara yang telah dilakukan, yaitu :
a. Call Center
Call Center adalah layanan via telepon yang melayani wajib pajak guna penyebaran informasi mengenai administrasi wajib pajak.
b. e-Samsat 
layanan pembayaran pajak kendaraan bermotor dan pengesahan STNK dengan cara melakukan pembayaran melalui ATM bank yang telah bekerja sama di seluruh wilayah di Indonesia. Adapun bank tersebut meliputi Bank BCA, Bank BRI, Bank BNI dan CIMB Niaga.

c. Aplikasi Kendaraan Bermotor

Aplikasi kendaraan bermotor bernama "Info Pajak Kendaraan Sulut" juga merupakan bagian dari $e$-Samsat yang berisi layanan penyediaan informasi mengenai data kendaraan dan data pajak kendaraan bermotor dari setiap kendaraan bermotor yang terdaftar pada Unit Pelayanan UPTD Minsel.

\subsection{Pembahasan}

Prosedur Penerimaan Pajak Kendaraan Bermotor dan Bea Balik Nama Kendaraan Bermotor (PKB dan BBNKB). Berdasarkan hasil penelitian, menunjukan bahwa perusahaan sudah memakai SOP (Standart Operational Prosedur) yang membuat penerimaan pajak berjalan sesuai dengan peraturan yang ada dan telah di bagi masing-masing fungsi yang berkaitan langsung dengan pelanggan untuk penerimaan pajak kendaraan bermotor dan bea balik nama kendaraan bermotor. Dalam hasil penilitian Mokoginta (2015). Dengan judul Analisis Efektivitas Produk Pemungutan Pajak Kendaraan Bermotor dan Bea Balik Nama Kendaraan Bermotor Peningkatan PAD Provinsi Sulawesi Utara. Menyatakan bahwa prosedur pemungutan yang dilakukan sudah berjalan efektif dengan pembagian tugas yang telah terstruktur serta realisasi penerimaan pajak kendaraan bermotor dan bea balik nama kendaraan bermotor dari tahun 2009-2013 melebihi target, sehingga termasuk dalam kategori sangat efektif.

Dasar Pengenaan Pajak Kendaraan Bermotor dan Bea Balik Nama Kendaraan Bermotor. Dasar pengenaan pajak adalah nilai berupa uang yang dijadikan sebagai dasar untuk menghitung pajak kendaraan bermotor dan bea balik nama kendaraan bermotor yang terhutang dengan cara mengalikan tarif pajak dengan menggunakan dasar pengenaan pajak. Tarif pajak tersebut adalah nilai jual kendaraan bermotor yang telah ditetapkan oleh menteri dalam negeri.

Tarif Pajak Kendaraan Bermotor Dan Bea Balik Nama Kendaraan Bermotor UPTD Minsel. Hasil penelitian dari Silvia dkk (2015). Menyatakan dalam pemungutan pajak kendaraan bermotor dalam pembelian kendaraan bermotor baru dikenakan tarif pembelian pertama ( $1,5 \%$ ) untuk pembelian kendaraan bermotor kedua dikenakan tarif ( $2 \%$ ) dan seterusnya, sedangkan bea balik nama kendaraan bermotor I (BBNKB I) adalah suatu biaya yang dikenakan pada saat masyarakat membeli kendaraan baru yang keluar dari dealer. Bea balik nama kendaraan bermotor II (BBNKB II) adalah biaya kendaraan yang telah dijual oleh pemilik sebelumnya pada pemilik yang baru. Sesuai dengan peraturan yang sudah diserahkan dalam bentuk penyerahan pada pihak lain wajib dilaporkan pada kantor badan pengelola pajak dan retribusi daerah untuk mengetahui jumlah biaya yang dikenakan dan pada saat jatuh tempo.

Perhitungan Pajak Kendaraan Bermotor dan Bea Balik Nama Kendaraan Bermotor. Siahaan (2016:91) "Besarnya pokok pajak dihitung dengan cara mengalikan tarif pajak dengan dasar pengenaan pajak. Cara perhitungan ini digunakan untuk setiap jenis pajak daerah, yang juga merupakan dasar perhitungan untuk semua jenis pajak pusat". Pada penelitian Madundang (2014) Menyatakan bahwa cara untuk menghitung besarnya PKB terutang dihitung berdasarkan perkalian antara tarif PKB dengan dasar pengenaan PKB.

Upaya Untuk Meningkatkan Penerimaan Pajak Kendaraan Bermotor dan Bea Balik Nama Kendaraan Bermotor. Strategi meningkatkan penerimaan pajak kendaraan bermotor (PKB) sudah dilakukan sesuai dengan strategi dalam meningkatkan penerimaan. Dalam melakukan upaya meningkatkan kerjasama tim dalam kelompok diutamakan untuk pencapaian target secara optimal. Sudah dilakukan di UPDT Minahasa selatan yaitu 
melakukan sosialisasi di segala bidang menganai PKB dan BBNKB, serta sering bekerjasama dengan kepolisian untuk melakukan Razia sehingga bisa mencari dan mendapatkan wajib pajak yang belum atau tidak melakukan kewajibannya untuk membayar pajak. Sistem Pelayanan Untuk membuat wajib pajak merasa nyaman dalam melaksanakan kegiatan pembayaran pajak. dengan adanya upaya ini diharapkan perusahaan dapat meningkatkan pencapaian target secara optimal.

\section{KESIMPULAN DAN SARAN}

\subsection{Kesimpulan}

Berdasarkan uraian pada hasil penelitian dan pembahasan, maka penulis menarik kesimpulan sebagai berikut :

1. Prosedur pemungutan penerimaan pajak kendaraan bermotor dan bea balik nama kendaraan bermotor sudah optimal dalam pemungutan pajak. Dikarenakan UPTD Minahasa Selatan telah mengikuti SOP (Standard Operating Procedure).

2. Masih adanya beberap kendala dalam pelaksanaan pemungutan Pajak Kendaraan Bemotor pada UPTD Samsat Minahasa Selatan, antara lain:

a. Masih rendahnya kesadaran Wajib Pajak untuk melaksanakan kewajibannya membayar pajak.

b. Data wajib pajak yang sering tidak lengkap.

c. Pemindahtanganan kendaraan bermotor tanpa di balik nama.

d. Pemilik kendaraan berpindah tempat kedaerah lain.

e. Penarikan kendaraan bermotor dari pihak pembiayaan tanpa ada laporan dari pihak pemilik kendaraan bermotor ataupun dari pihak pembiayaan itu sendiri.

3. Upaya yang dilakukan pemerintah kabupaten Minahasa Selatan adalah sebagai berikut :

a. Melakukan sosialisasi kepada wajib pajak melalui media masa dan sosial media.

b. Kerja sama dengan kepolisian untuk mendapatkan data wajib pajak yang belum atau tidak melakukan pajak dan bea balik nama kendaraan.

3. Melakukan sistem pelayanan untuk membuat wajib pajak merasa nyaman dengan cara membuat layana Call Center dan $e$-Samsat.

\subsection{Saran}

Melihat hasil penelitian yang menunjukan bahwa penerimaan pajak kendaraan bermotor dari tahun 2015-2017 mengalami meningkat, maka peneliti memberikan saran:

1. Pemerintah Daerah. Pemerintah daerah Minahasa Selatan harus lebih giat lagi dalam melakukan peningkatan pada pelayanan, baik itu dalam sistem pembayaran pajak maupun dari sistem yang lainnya, serta dalam hal penetapan target penerimaan pajak.

2. Peneliti selanjutnya. Peneliti selanjutnya supaya melakukan penelitian di beberapa atau seluruh sampel kota/ kabupaten dari suatu provinsi agar menghasilkan penelitian yang berakurat.

\section{DAFTAR PUSTAKA}

Ashari U (2013) Implementasi Kebijakan Penerimaan Pajak Dan Bea Balik Nama Kendaraan Bermotor II Pada Kantor UPTD Sistem Administrasi Manunggal Satu Atap Di Kabupaten Bulungan. E-Journal Administrative Reform, 2013, Hal 511524

Gnap J (2015) Pajak kendaraan bermotor di republik Slowakia dan dampaknya Dalam konteks desentralisasi fiskal. Journal International and Procedia Economics Finance 34 ( 2015 ) $344-351$

Halim Abdul \& Muhamad S Kusufi (2014). Akuntansi Keuangan Daerah. Edisi 4, Jakarta: Salemba 
Lubis Irsan. (2015) Mahir Akuntansi Pajak Terapan. Andi Yogyakarta

Laowo E Theresia (2016) Analisis Prosedur Dan Perhitungan Bea Balik Nama Kendaraan

Bermotor Pada Kantor Bersama Samsat Manado. Jurnal EMBA Vol.4 No.4 Desember 2016, Hal. 974 - 983

Mardiasmo (2016). Perpajakan. Edisi Revisi Terbaru. Yogyakarta. Penerbit Andi

Masirete M Iswan (2013) Strategi Peningkatan Penerimaan Pajak Kendaraan Bermotor Dalam Rangka Meningkatkan Pendapatan Asli Daerah (PAD) Kabupaten Poso. Jurnal EKOMEN Vol. 13 No. 2 - September 2013.

Makalus O (2016). Analisis Penerimaan Pajak Biaya Kendaraan Bermotor Dan Bea Balik Nama Kendaraan Bermotor Pada Kantor Dinas Pendapatan Darah Di Provinsi Sulawesi Utara. Jurnal EMBA 13 Vol. 4 No. 2 Juni 2016, Hal. 013-021

Mulyadi. (2001). Sistem Akuntansi. Jakarta: Salemba Empat

Ofoegbu N. Grace (2016) Analisis Empiris Dari Pengaruh Pajak Pendapatan Terhadap Ekonomi Pengembangan Nigeria. International Journal of Asian Social Science, 2016, 6(10): 604-613

Pangalila I. Indinisya (2015). Analisis Pelaksanaan Sistem Pemungutan Pajak Kendraan

Bermotor Di Kota Manado. Jurnal EMBA 9 Vol.3 No.1 Maret 2015, Hal. 9-16

Sugiyono, (2015) Metode Penelitian Kuantitatif Kualitatif Dan $R \&$ B Alfabeta, Bandung

Simanjuntak H, Timbul \& Muhlis I (2012) Analisis Kepatuhan Pajak dan Dampak

Tentang Anggaran Daerah dan Kesejahteraan Masyarakat. International Journal of

Administrative Science \& Organization, September 2012 Volume 19, Number 3 page 195-205

Sedarmayanti Dan Syarifudin H (2011) Metodologi Penelitian. Mandar Maju, Bandung

Sujarweni Wiratna V (2015). Sistem Akuntansi. Pustaka Baru Press. Yogyakarta.

Tahar A \& Zakhiya M (2011) Pengaruh Pendapatan Asli Daerah Dan Dana lokasi Umum Terhadap Kemndirian Daerah Dan Pertumbuhan Ekonomi Daerah.Jurnal Akuntansi dan Investasi Vol. 12 No. 1, halaman: 88-99, Januari 2011

Waluyo. (2013). Perpajakan Indonesia. Salemba Empat, Jakarta 